\title{
EL PERSONAJE Y LA RETÓRICA DEL NOMBRE PROPIO EN LOS LIBROS DE CABALLERÍAS ESPAÑOLES
}

\author{
María Carmen Marín Pina \\ Universidad de Zaragoza
}

Tristán, Lanzarote, Amadís, Esplandián, Palmerín son nombres propios que encierran el poder mágico de la palabra, pues por sí solos transportan a un tiempo lejano, evocan el mundo de la caballería y recuerdan apasionadas historias de amor y peligrosas batallas. Remiten a unos libros, los de caballerías, en los que la onomástica (antropónimos y topónimos) cobra a su vez especial relevancia por convertirse en un elemento auxiliar en la configuración del espacio de la aventura y del personaje, a la par que en un puro juego verbal.

\section{LA IMPOSICION DEL NOMBRE}

La inmensa mayoría del amplio número de personajes que puebla estas obras se identifica con nombres propios. Algunos son bíblicos, otros clásicos, también los hay de procedencia oriental ${ }^{1}$ y sacados de las tres materias cantadas por los versos de Jean

1.- Aunque de ellos no vamos a ocuparnos, abundan sobre todo en el Zifar, como han estudiado J. Burke, "Names and the Significance of Etymology in the Libro del Cavallero Cifar", RR, 59, 3 (1968), pp. 161-173; J. Pelegrin-Battesti, «Signes et marques de l'Orient: de l'utilisation de l'onomastique dans le Libro del Caballero Cifarm, en Images et signes de l'Orient dans l'Occident médieval (Littérature et civilisation), Provenza, CUERMA, 1982, pp. 285-298. En los textos posteriores son también frecuentes en virtud de las muchas aventuras que los caballeros acometen en tierras orientales. Para otra ocasión dejamos el estudio de la toponimia y el de la repercusión de la onomástica caballeresca en la vida real. 


\section{MARIA CARMEN MARÍN PINA}

Bodel. Del ciclo troyano y artúrico los autores toman prestados diversos nombres o imitan sus técnicas compositivas, según han estudiado Williams, García de la Riega, Lida de Malkiel o Avalle-Arce ${ }^{2}$. Otros muchos nombres en cambio son de nueva creación, sonoros, ingeniosos, a veces chocantes y un tanto rimbombantes, como advirtió ya el hidalgo manchego, que descubrió en la onomástica el paso franqueable para ingresar en el mundo de la ficción que lo llevará a la locura ${ }^{3}$. En la redacción de su imaginaria historia caballeresca, don Quijote bautiza a sus protagonistas con nombres inventados según la retórica del género, siguiendo los principios y reglas que sirvieron a los escritores de libros de caballerías para acuñar los suyos. Al igual que para los autores caballerescos, el nombre es para don Quijote una manera de construir la identidad del personaje.

En el momento de su nacimiento se le impone al personaje un nombre de pila que es el que lo identifica en los primeros años de su vida. Muchos de estos nombres no encierran sentido o significación alguna, pero otros sí, y definen, como en la antigüedad y en las más diversas tradiciones, la esencia del personaje que lo lleva. Amadís, por ejemplo, aunque se nombra así en recuerdo del santo del mismo nombre venerado por Darioleta, lleva en su propia denominación la esencia de su comportamiento, su condición de leal amador ${ }^{4}$. Lo mismo puede decirse de Plazer de mi vida en el Tirante, del gigante Pavoroso en el Palmerín de Inglaterra o de las discretas doncellas Clandestria y Fidelia en el Espejo de príncipes y cavalleros, por citar tan sólo algunos ejemplos de nombres que definen por sí solos a los seres que identifican. Siguiendo una larga tradición filosófica, filológica y mística, los nombres de ciertos personajes caballerescos reflejan, pues, sus cualidades esenciales, cualidades que en ocasiones son destacadas a través de una pequeña glosa etimológica en la que se descubren incluso algunos de los mecanismos y principios que rigen su formación.

2.- Del cotejo de la onomástica troyana, tristánica y artúrica en relación con el Amadís de Gaula se ocupa G. S. Williams, "The Amadis Question", RHi, XXI (1909), p. 58 y ss. C. García de la Riega, Literatura galaica. El Amadís de Gaula, Madrid, 1909, citado por María Rosa Lida de Malkiel, «EI desenlace del Amadís primitivon, en Estudios de literatura española y comparada. Buenos Aires, Eudeba, 1966, p. 155, relaciona los sufijación amadisiana con la de los textos del ciclo troyano. La onomástica en el Amadis de Gaula ha sido recientemente estudiada por J. B. Avalle-Arce, "Amadis de Gaulan, el primitivo y el de Montalvo, México, F. C. E., 1990, p. 167 y ss., así como pp. 418-419, si bien ya se ocupó de la rica y sugestiva polionomasia del texto amadisiano en Nuevos deslindes cervantinos, Barcelona, Ariel, 1975. En el caso del Amadís, la onomástica es un excelente punto de partida para tratar el asunto de las fuentes.

3.- La onomástica quijotesca ha sido estudiada, entre otros, por P. Salinas, "El polvo y los nombres", en Ensayos Completos, 3, Madrid, Taurus, Persiles, 1983, pp. 97-110; L. Spitzer, «Perspectivismo lingüístico en el Quijotem, en Lingüística e historia literaria, Madrid, Gredos, 1955, pp. 161-225; E. C. Riley, "Who's who in Don Quijote? or an Approach to the Problem of Identity", $M L N$, (1966), pp. 113-130; H. Mancing, "The Comic Function of Chivalric Names in Don Quijote», Names, 21 (1973), pp. 220-235; D. Reyre, Dictionnaire des noms des personnages du don Quichotte de Cervantes suivi d'une analyse structurale et linguistique, París, Éditions Hispaniques, 1980, aunque presenta algunos errores en la identificación de las fuentes caballerescas. Para el de Dulcinea en concreto, vid. R. Lapesa, "Aldonza - dulce-Dulcinea", BBMP, XXIII (1947), pp. 48-53, y H. lventosch, «Dulcinea nombre pastoril", NRFH, 17 (1963-1964), pp. 60-81.

4.- Para la onomástica en el Amadís de Gaula, vid. la edición de Juan Manuel Cacho Blecua, I, Madrid, Cátedra, 1987, p. 145. Como él mismo explica, en el caso de Amadís se ha de relacionar su nombre con el amor. 


\section{La invención etimológica}

La explicación etimológica de algunos nombres propios practicada por los escritores caballerescos entronca, como hemos dicho, con una larga tradición, según la cual a través del análisis e interpretación del nombre se llega al conocimiento de las cosas y al descubrimiento de la verdad ${ }^{5}$. La etimología tenía un valor de conocimiento teórico y a ella se unía con frecuencia la interpretación simbólica, consistente en tratar las cosas mismas como signos y en desentrañar sus significaciones ${ }^{6}$. En concreto, la interpretación retórica de los nombres propios pasó de los panegíricos de la tardía Antigüedad pagana a la poesía eclesiástica, a los himnos, y en el siglo XII el procedimiento se consideraba también en las poéticas como una forma de interpretatio dentro de la amplificación ${ }^{7}$. Entendida como método explicativo, la etimología se descubre a través del juego verbal y es por ello por lo que resulta casi siempre un ingenioso procedimiento artístico. Este recurso tan explotado por los predicadores medievales en sus sermones y por los poetas en sus obras, lo mismo que por los cultivadores del género pastoril, los místicos y otros escritores renacentistas ${ }^{8}$, alcanza también al género caballeresco.

Aunque la tradición era antigua y la práctica estaba muy generalizada, los autores de estos libros también pudieron aprenderla en los textos artúricos y en las breves historias de aventuras caballerescas, que ya habían recurrido a estos juegos ${ }^{9}$. Perceval o Tristán

5.- Una tradición cuyos orígenes hay que buscarlos tanto en el Antiguo Testamento, donde se explica ya el sentido de muchos nombres, como en el cristianismo patrístico que tanto influirá después en las Etimologías isidorianas (vid. Etimologías, I, ed. bilingüe de J. Oroz Reta y M. A. Marcos Casquero, Madrid, BAC, 1982, p. 321, item 29; E. De Bruyne, Historia de la Estética, II, Madrid, BAC, 1983, pp. 414-415), y en los filósofos y teólogos medievales. Para su valor en los textos clásicos y medievales, vid. E. R. Curtius, «La etimología como forma de pensamiento», en Literatura europea y Edad Media latina, Madrid, FCE, 1948, 1984 4. ${ }^{\mathrm{a}}$ reimp., pp. 692-699; R. Guiette, «Linvention étymologique dans les lettres françaises au Moyen Âge», en Forme et senefiance, études médiévales recueillies par J. Dufournet, M. De Grève et H. Braet, Ginebra, Librairie Droz, 1978, pp. 87-98.

6.- E. Gilson, La filosofía de la Edad Media, I, Madrid, Gredos, Biblioteca Hispánica de Filosofía, 1958, pp. 402-408. El público medieval estaba acostumbrado a este simbolismo no sólo por la literatura que consumía, sino por el medio en el que vivía, vid. R. Guiette, "Simbolisme et senefiance au Moyen Âge», en Forme et senefiance, op. cit., pp. 29-45.

7.- Cicerón, De inventione, 1, 24; Quintiliano, V, 10, 30. Vid. E. R. Curtius, op. cit., p. 696; E. Faral, Les arts poétiques du XII et du XIII siècle. Recherches et documents sur la technique littéraire du Moyen Âge, París, Champion, 1924; rept. Ginebra, Slatkine, 1982, p. 65. Para ver los distintos sentidos que a lo largo de la historia ha tenido el término, vid. P. Zumthor, «Étymologies», en Langue, texte, énigme, Paris, Seuil, 1975, pp. 144-160.

8.- La onomástica pastoril ha sido estudiada detenidamente por H. Iventosch, Los nombres bucólicos en Samnazaro y la pastoral española, Valencia, Castalia, 1975. De gran interés es en la época renacentista la teoría luisiana sobre el nombre. Con su sólida formación humanista y hebraica, Fray Luis de León la expone en las páginas introductorias del primer libro ( (De los nombres en general») De los nombres de Cristo (ed. de C. Cuevas, Madrid, Cátedra, 1986, 5. a ed., pp. 86-95 y 153-170). Sobre la misma, vid. E. Köhler, «Fray Luis de León et la théorie du nom», BHi, L (1948), pp. 421428.

9.- Para el estudio de la onomástica artúrica en general son de interés los trabajos de L. F. Flutre, Table des noms propres avec toutes leurs variantes figurant dans les romans du Moyen Age écrits en français ou en provençal, Poitiers, Centre d’Études Supérieures de Civilisation Médiévale, 1962; G. D. West, An Index of Proper Names in French Arthurian Prose Romances, Toronto, 1978; Ch. and R. Moorman, An Arthurian Dictionary Prose Romances, Mississippi, University Press, 1978. 


\section{MARÍA CARMEN MARIN PINA}

son, por ejemplo, dos nombres que reciben ya una interpretación simbólica y etimológica. Desde su nacimiento, Tristán lleva en su nombre vaticinado el triste sino de su existencia, como su madre, la reina Blancaflor, señala tras el parto: «Triste te he traído al mundo, triste es la primera fiesta que puedo hacerte, por ti siento tristeza de morir. Y como has llegado al mundo en medio de la tristeza, tu nombre será Tristán»10.

En los textos españoles se repiten también estos juegos verbales en determinados antropónimos y su etimología se descubre por algunas de las vías apuntadas por San Isidoro, por la mera atracción homonímica o por los procedimientos más inverosímiles. Como Tristán, Gridonia se llama así porque «en aquella tierra que dizen por el llorar gridar y porque nació en tiempos de tantos gritos y lloros pusiéronle nombre Gridonia» (Primaleón fol. lvij v) ${ }^{11}$, aunque en este caso el nombre sea un derivado postverbal, y no adjetival, que recordará en el futuro los llantos hechos al tiempo de su nacimiento con motivo de la muerte de su padre Nardides. En el nombre de Penamundi se profetiza en cambio el triste fin que corrcrán todos aquellos que aspircn a su amor, pucs, cn palabras de Doroteo, "Un gran sabio la puso por nombre Penamundi, al tiempo de su nacimiento, por razón de la pena que había de dar a todos cuantos la miraban ${ }^{12}$. Simbolismo bien distinto se esconde por el contrario en el de Gaudencio que, respetando el sentido de su étimo latino, recibe tal apelativo «porque se á de alegrar mucho su padre cuando le conosciere por hijon (Platir fol, xxviij v).

Está claro que en el nombre de pila se vaticinan sucesos del porvenir del personaje y/o se fijan pormenores del nacimiento que podrán determinar su futuro más inmediato. Su nombre deriva en ocasiones del lugar en el que es alumbrado o abandonado tras el parto. A Florestán, por ejemplo, se le impone tal nombre por haber venido al mundo en medio de una floresta (Amadís de Gaula, II, XLII, p. 628) ${ }^{13}$. Palmerín de Olivia, como Moisés (Éxodo, II, 10) o el Espinelo del romance ${ }^{14}$, debe el suyo al marco natural al que es confiado y del que es recogido por el colmenero Geraldo, «e porque lo falló entre las palmas e olivas púsole nombre Palmerín» ${ }^{15}$. El topónimo "de Olivia» responde al nombre

10.- Tristán e Iseo, ed. de Alicia Yllera, Madrid, Cupsa, 1978, p. 74. Como explica Martín de Riquer (La leyenda del graal y temas épicos medievales, Madrid, Prensa Española, El Soto, 1969, p. 38), el nombre de Perceval es genuinamente francés y encierra también una explicación etimológica (percer $=$ atravesar $/ v a l=$ valle) relacionada con su experiencia vital. Para su interpretación, vid., además, J. R. Resina, La búsqueda del Grial, Barcelona, Anthropos, 1988, pp. 93-94.

11.- Citamos por la edición salmantina de 1512.

12.- Beatriz Bernal, Don Cristalián de España, edición modernizada con introducción de S. Park, UMI, Ann Arbor, 1981, p. 300.

13.- Su nombre se presta a un juego nominal en el Lisuarte de Grecia, Sevilla, 1525, donde uno de los personajes le da una interpretación simbólica: «Vos, buen rey, por florescer en vuestras bondades no me quesistes olvidar, que quien os puso el nombre, muy bien os lo supo poner» (fol. $x x y$ v).

14.- Si Moisés significa en hebreo «Sacado de las aguas», Espinelo podría ser "Recogido en la mata del espino», lugar hasta donde las ondas del mar lo condujeron: «a la sombra de una mata/que por nombre espino había, que por eso me pusieron/de Espinelo nombradia». El romance, publicado por primera vez por Juan de Timoneda en su Rosa de amores (Valencia, 1573), lo relacionó ya J. B. Avalle-Arce, "El nacimiento de Amadís", en Essays on Narrative Fiction in the Iberian Peninsula in Honour of Frank Pierce, Londres, The Dolphin Book, 1982, p. 19, y F. Delpech, «Les jumeaux exclus: cheminements hispaniques d'une mythologie de l'impureté», en Les problemes de l'exclusion en Espagne (XVI ${ }^{e}-X V I I^{e}$ siecles), études reuniés et presentées par A. Redondo, París, Publications de la Sorbonne, 1983, p. 180. Para más datos, J. Falk, "The Birth of the Hero in the Romancero», La Corónica, 14 (1986), pp. 220-229.

15.- Palmerin de Olivia, ed. de G. di Stefano, Pisa, Università di Pisa, 1966, p. 39. 
de la montaña y es el clásico sintagma que caracteriza a los caballeros por su procedencia y que la picaresca y Cervantes caricaturizarán ${ }^{16}$. Por analogía de situaciones y en recuerdo del triste nacimiento de Palmerín, su hija Flérida impone a uno de sus hijos el nombre de Floriano del Desierto, «por que la floresta en que naciera se llamara del Desierto, como por ser en tiempo que el campo estaba cubierto de flores; él en sí tan hermoso, que el nombre parescía dino dél, y él no del nombre» ${ }^{17}$. La misma técnica sigue también Beatriz Bernal al idear el sobrenombre con el que se identifica a uno de los hijos gemelos de Dorante: «El uno que primero nació se llama Dismael de la Roca, por cuanto a la princesa Agolandria le tomó el parto cabe una roca que junto a un puerto de mar estaba [...]; y de allí a tres horas nació el segundo, y ha nombre Guiladoro el Rubio, por razón de los hermosos cabellos que ha» (Cristalián de España, p. 316).

El color de los cabellos entra dentro del conjunto de los rasgos físicos que determinan también, entre otras cosas, el nombre o sobrenombre del personaje. Del gigante Mayortes que aparece en el Irimaleón se glosa su antropónimo con una explicación linguísticosemántica: «Y este gigante se llamava Mayortes y por esso era más grande y fermoso que otro que en la isla uviesse por ser gigante» (Primaleón fol. 1xiiij r). La condición gigantesca del personaje se justifica a través de un adjetivo calificativo en grado comparativo «mayor», modificado por el sufijo -tes. Pese a todo, en la glosa el nombre no se adecúa a la persona, sino la persona al nombre: «se llamava Mayortes y por esso era más grande y fermoso».

Giber, uno de los caballeros aspirantes al amor de Gridonia, debe su apelativo a la giba que lleva, aunque en su interpretación etimológica la palabra se sustituya por corcova: «Era alto de cuerpo y muy feo de gesto, y tenía una corcoba grande y por esto le llamavan el cavallero Giber» (Primaleón fol. lxxvj r). En todos los casos el nombre define al personaje por alguna de sus cualidades físicas, aspecto éste que contribuirá a su caracterización, como también sucede en el caso Sancho Panza o Zancas, que tenía «la barriga grande, el talle corto y las zancas largas, y por esto se le debió de poner el nombre de Panza y de Zancas» $(D Q$, I, 9, p. 102).

Junto a los rasgos físicos están igualmente las marcas de nacimiento como determinantes del nombre. Flores, cruces, armas figuradas, signos celestes y luminosos, así como letras cabalísticas, son algunas de las insólitas señales que los caballeros, y en menor medida las doncellas, muestran en su cuerpo al tiempo de su alumbramiento. Estas extrañas marcas, explicables dentro de la compleja tradición fisiognómica ${ }^{18}$, vaticinan de algún modo el nacimiento de un personaje carismático, heroico, como en los más antiguos relatos folclóricos y míticos. Estos signos somáticos, cargados de un simbolismo pocas veces interpretado por los autores, son los que dan nombre propio o sobrenombre a los

16.- Lazarillo de Tormes, ed. de F. Rico, Madrid, Cátedra, 1987, p. 49, nota 8; Cervantes, El ingenioso hidalgo don Quijote de la Mancha, ed. de M. de Riquer, Barcelona, Planeta, 1983, 4. ${ }^{a}$ ed., p. 38. 17.- Francisco de Morais, Libro del muy esforçado cavallero Palmerín de Inglaterra, en Libros de Caballerias. Segunda Parte (Ciclo de los Palmerines, extravagantes, glosario, variantes, correcciones e indices), ed. de Adolfo Bonilla y San Martín, Madrid, NBAE, 1908, p. 9 b.

18.- Estudiada por F. Delpech, "Les marques de naissance: physiognomonie, signature magique et charisme souverain", en Le corps dans la société espagnole des XVI" et XVII" siècles, Colloque International (Sorbonne, 5-8 octobre, 1988), études reunies et presentées par A. Redondo, París, Publications de la Sorbonne, 1990, pp. 21-49. Vid. también del mismo autor, "Du héros marqué au signe du prophète: esquisse pour l'archéologie d'un motif chevaleresque», Hommage à Maxime Chevalier, BHi, 92 (1990), pp. 237-257. 


\section{MARÍA CARMEN MARÍN PINA}

personajes y los que se prestan también al juego etimológico. El antropónimo alude entonces a dicha señal y resume así la esencia heroica del personaje que habrá de demostrar y consolidar en su andadura. Si Esplandián (Amadís de Gaula, III, LXVI, p. 1004) y Cirongilio vienen ya al mundo con su nombre escrito en el cuerpo ${ }^{19}$, a Luciana se le impone por la estrella roja que adorna su pecho izquierdo, "por la que la llaman por su lucero Lucianas (Lisuarte, fol. lxxxiv v); al Caballero del Febo, por la resplandeciente cara figurada en el lado de su corazón y a su hermano Rosicler por la rosa blanca y colorada impresa en su pccho ${ }^{20}$.

Flores en el pecho o en el brazo justifican también los nombres de Floriseo, Florambel o Clarisel de las Flores ${ }^{21}$. Sea por las flores que adornan su cuerpo o por haber nacido en un lugar donde las hubiere, lo cierto es que muchos de los protagonistas de estos libros llevan en su nombre la raíz de la flor, imagen arquetípica del alma, de la belleza y de la fugacidad. Florisando, Floriseo, Florindo, Florambel de Lucea, Florisel de Niquea, Florando de Inglaterra, Floramante de Colonia, etc., son, en expresión típica del género, la flor de la caballería, lo más granado de la orden a la que pertenecen ${ }^{22}$. La que lleva Floriseo tiene forma de cruz, señal que también porta en su pecho Lisuarte y por la que se le identifica con el sobrenombre de Caballero de la Vera Cruz (Lisuarte de Grecia, fol. $\mathrm{x}$ v), lo mismo que a Amadís de Grecia se le conoce como el donzel de la Ardiente Espada, «que assí se llamava por la que en el pecho tenía» ${ }^{23}$.

En otros casos la explicación etimológica se descubre a través de un mero juego verbal. En una glosa al Laborintus de Évrard l'Allemand, se señalan distintos modos de realizar la interpretatio: «aliquando fit per litteras, aliquando per syllabas, aliquando per dictiones) ${ }^{24}$. Los procedimientos etimológicos apuntados en la glosa de este tratado de poética medieval los siguen practicando los autores caballerescos en la acuñación de los antropónimos. Los nombres de los recién nacidos se forman a partir de las sílabas que

19.- Cirongilio de Tracia, Sevilla, 1545, ed. de J. R. Green, UMI, Ann Arbor, 1974. Cirongilio lleva esculpido "en el su braço derecho diez letras bermejas a manera de fuego" (p. 21), letras griegas descifradas por un ermitaño que «puso nombre al donzel Cirongilio conforme a la sentencia de las diez letras que en su derecho braço tenía señaladas" (p. 28). Para el caso de Esplandián, vid. Paloma Gracia Alonso, «El nacimiento de Esplandián y el folclore», comunicación presentada al III Congreso de la Asociación Hispánica de Literatura Medieval, en prensa. Signos todos ellos que F. Delpech, art. cit., p. 47, explica a la luz de la tradición judeo-islámica.

20.- «Y Clandestria, con mucha gracia, puso nombre a los niños. Al que primero havía nascido llamó el Cavallero del Febo, por la figura que en él vido en el lado izquierdo, sobre el coraçón. Y al segundo llamó Rosicler, por la rosa de los pechos. Desto huvo gran plazer la princessa, diziendo que les havía puesto los sobrenombres conformes a los que ellos merescían», Diego Ortúñez de Calahorra, Espejo de príncipes y cavalleros, I, ed. de D. Eisenberg, Madrid, Espasa-Calpe, Clásicos Castellanos, 1975, pp. 93-94.

21.- «Mirándole vieron que tenía encima del coraçón una flor colorada hecha en la carne a manera de cruz, a cuya causa en su bautismo le pusieron por nombre Floriseom, Fernando Bernal, Floriseo, Valencia, 1516, fol. ij r; la de Florambel es a manera de violeta, Enciso, Florambel de Lucea, Valladolid, 1532, fol. xxix r; P. Geneste, Le capitaine-poète aragonais Jerónimo de Urrea, sa vie et son oeuvre ou chevalerie et renaissance dans l'Espagne du XVI siècle, París, Ediciones Hispanoamericanas, 1978 , p. 465.

22.- Expresión estudiada por L. Spitzer, «Fleur et rose synonymes par position hiérarchique», en Romanische Literatur Studien 1936-1956, Tübingen, 1959, p. 815.

23.- Feliciano de Silva, Amadís de Grecia, Burgos, 1535, fol. vij v, aunque a ella se alude ya en el último capítulo de Lisuarte de Grecia, fol. cxij r.

24.- E. Faral, op. cit., p. 65. 
figuran en los de sus padres (interpretatio per syllahas). T.a reina de Tarsis, por ejemplo, impone a su hijo el nombre de Polendos "porque tomasse los nombres de Palmerín e de su abuelo Florendos, porque eran la flor de la cavallería del mundo e también porqu'en aquella tierra quería dezir 'hurtado'” (Palmerín de Olivia, p. 309). El autor intenta un doble juego etimológico que no logra en su totalidad porque el nombre propuesto, Polendus, no resulta de la combinación de las sílabas que figuran en los nombres de sus abuelos, Palmerín y Florendos. Los traductores franceses, olvidándose del sentido figurado que el nombre podía tener según la glosa narradora (Polendos = hurtado, concebido con engaños), lo cambian por Palmendos. Del mismo modo, Flortir lleva unidas en su nombre las sílabas que conforman los patronímicos de sus padres Florinda y Platir, lo mismo que Florambel (hijo de Florineo y Beladina), Florismarte (hijo de Flosarán y Martedina) - Darnandro (hijo de Darineo y Aliandra) ${ }^{25}$, etc.

El juego puede simplificarse y una sola sílaba del nombre de la persona a la que se quiere homrar y recordar puede bastar en otros casos para la formación de uno nuevo. Duardén lleva el suyo en honor de su padre don Duardos (Primaleón, fol. ccvj v), Rifarán al convertirse al cristianismo tomará el de Triolo por su padre Trineo (Primaleón, fol. xliiij v), Polindo en recuerdo de su madre Polimira (Polindo, fol. xv v) ${ }^{26}$, etc.

Más ingeniosa resulta, sin embargo, la interpretatio per dictiones. Para explicitar su significado, los autores descomponen el compuesto y comentan cada una de sus partes. Al ejemplo ya citado de Penamundi, pucde sumarse el de Bclforte, así llamado "porque salió el más bello que en grandes partes se pudiesse hallar y el más fuerte y bravo de coraçón» (Platir, fol. vij r). El comentario de los dos adjetivos del compuesto se realiza en grado superlativo: el más bello (bel) y el más fuerte (forte) como exige la presentación del futuro caballero. Idéntico procedimiento emplea el autor en la glosa del nombre del tullido caballero Belcento: «que vos digo que á bien cient años que vos dessean mis ojos ver; por esto me llaman a mí el Belcento, que este fue el nombre que me puso a mí mi madre [...] y dexó escripto que fuesse este mi nombre porque avía de allegar a cient años» (Platir, fol. cxj r). En la misma línea está el de la altiva Miraguarda, que «era mucho para ver y mucho más para se guardar della» (Palmerín de Inglaterra, p. 94 a). Maestro insuperable como inventor de nombres curiosos hasta la época de Cervantes y

25.- «Luego que ovo nacido el infante le baptizaron Vernao y Triola y le pusieron nombre Flortir, tomando la meitad de Florinda y la otra meitad de Platirs, Platir, Valladolid, 1533, fol. cxiij v. A Florambel su madre le impone tal nombre por la señal de su brazo: «y pues que con tal señal naciste, mi voto es que ayas por nombre Florambel de Lucea porque le alcançe parte de tu belleza y también porque participemos d'él tu padre y yon Florambel, fol. xxix r. El nombre de Florismarte lo explica Pellicer en una nota a su edición del Quijote, I, Madrid, Gabriel Sancha, 1797, Parte I, cap. VI. La práctica la secundan los continuadores italianos, como se puede ver en el nombre de Darnandro, sacado del Libro secondo del valoroso cavallier Flortir, Venecia, 1581. Aunque sin recurrir al juego silábico, Martorell también funde de algún modo en el nombre de Tirante el Blanco el de sus progenitores: «A mí dizen Tirante el Blanco, porque mi padre fue señor de la marcha de Tirania [...] y mi madre fue hija del duque de Bretaña, y ha nombre Blanca» (Joanot Martorell, Tirante el Blanco, I, ed. de Martín de Riquer, Madrid, Espasa-Calpe, Clásicos Castellanos, 1974, p. 96).

26.- La creación de nuevos nombres a partir de las primeras sílabas del nombre de alguno de sus progenitores es un recurso utilizado con frecuencia, y sin ningún tipo de comentario, por los autores. En el Palmerín de Inglaterra es el caso, por ejemplo, de Francián el músico, hijo de Francelina; Belisarte y Rosbel, hijos de Belcar. En el Espejo de prfincipes y cavalleros, el de Bramarante, hijo Bradamán Campeón; Candriana, hija de Candramarte; Olivia, hija de Oliverio, etc. 


\section{MARÍA CARMEN MARÍN PINA}

Quevedo es Feliciano de Silva como ya apuntó Cravens ${ }^{27}$. Con este mismo procedimiento, y con el recuerdo del amadisiano Ardán Canileo (II, LXI, 867), acuña nombres como Archileo, Canifeo Cinofal, Canihonza, etc.

No siempre se descubre, sin embargo, la etimología. A veces el comentario se silencia y los autores dejan que sean los propios lectores los encargados de desvelar el juego simbólico que subyace en los nombres y que en ocasiones determina la esencia del personaje que lo lleva. Primaleón, Malfado, Polimira, Selvián, Iracandor, Bellaestela, Amplamira, Artimaga, Albamira, Clarimundo, Clarisol, Floramante, etc., son nombres compuestos que se prestan a ello si el público lo desea y se aviene al juego que el autor ha practicado en otras ocasiones.

\section{Derivación nominal}

Fuera de todos estos casos, los nombres propios de nueva creación resultan de una combinación de sílabas aparentemente sin orden ni sentido. La derivación por prefijación y por sufijación es el recurso más socorrido para dotar de nombre al amplísimo número de personajes que desfilan por estos libros. Con la derivación se desdibujan muchos nombres originales y se convierten en otros más sonoros: Alda se transforma en Alderina, Carmen en Carmela y Carmesina, Laura en Laurena y Laurencia, Leonor en Leonorina y Leonoreta, Pedro en Perequín, Esmeralda en Esmerinda, Estrella en Estrelleta, etc. Algunos de los prefijos usados tienen valor adjetival a la par que simbólico y se prestan a velados juegos nominales que el autor no se ocupa de airear y que se difuminan entre las otras sílabas del nombre. Es el caso de las raíces prefijales $F L O R$, ya comentada, $B E L$ (Belaquín, Belcar, Belsima), POLI (Polinarda, Pólita, Policia, Poliandra, Polier), CLAR (Clarián, Claribalte, Clarimundo, Clarisol) o el del término italiano BRANDA, espada, que ya Clemencín ${ }^{28}$ señaló como raíz frecuente en la formación de muchos nombres caballerescos (Brandamor, Brandimar, Brandafilio, Brandafuriel). Algunas de estas raíces son las mismas que conforman también los nombres de los libros de pastores, un género que, en opinión de Iventosch ${ }^{29}$, creó una onomástica casi totalmente nueva, que excluía por sistema las onomásticas germánica tradicional y la caballeresca, así como un gran número de nombres de santos y bíblicos. El análisis de los textos caballerescos demuestra, sin embargo, que existen al respecto una serie de principios retóricos comunes a ambos géneros que son los que determinan la acuñación de nombres idénticos o similares para pastores y caballeros. El contexto situacional y todo el ropaje de la aventura es el que dota al nombre de un sentido especial. La onomástica caballeresca es un crisol de géneros donde confluyen y se confunden las distintas modalidades de la ficción idealista, incluida también la pastoril.

27.- S. P. Cravens, Feliciano de Silva y los antecedentes de la novela pastoril en sus libros de caballerias, Valencia, Hispanófila, 1976, pp. 47 y 80. Siguiendo esta técnica, don Quijote acuña el nombre de Rocinante, «nombre, a su parecer, alto, sonoro y significativo de lo que había sido cuando fue rocín, antes de lo que ahora era, que era antes y primero de todos los rocines del mundo» $(D Q, \mathrm{I}, 1,37)$.

28.- Miguel de Cervantes, El Ingenioso hidalgo don Quijote de la Mancha, comentado por D. Clemencín, Madrid, Librería de la Viuda de Hernando, 1894, nota 18, I, XVIII.

29.- H. Iventosch, Los nombres bucólicos en Sannazaro y la pastoral española. Ensayo sobre el sentido de la bucólica en el Renacimiento, op. cit., pp. 32-33. Por otro lado, las raíces referidas al mundo vegetal y arcádico pueden hallarse también en nombres caballerescos como Flérida, Florendos, Selvida, Melisa, Silvia, Filadelfo, etc., todos ellos de la serie española palmeriniana. 
Gracias a una combinación de afijos, a un equilibrio de sílabas y sonidos, los autores crean nombres sonoros, atractivos homófonamente para los lectores o espantosos, como los de los gigantes Ferrobroca, Grutafora o Daligan de la Escura Cueva y Pandaro, «que sólo con los nombres hacían espanto" (Palmerin de Inglaterra, p. 19 a) por la mala fama que encerraban y quizá también por su tenebrismo. Frente a ellos otros provocan risa y contribuyen a la consecución del humor y a la presentación paródica del personaje, como sucede con el del hidalgo Camilote, coronado por ese sufijo -OTE que siempre encierra un matiz ridículo y que ya Dámaso Alonso relacionó con el que aparece después en el nombre de don Quijote ${ }^{30}$. Por el contrario, otros muchos no tienen ningún sentido y entrarían en el terreno de esa función lúdica del lenguaje propuesta por Francisco Ynduráin ${ }^{31}$. La musicalidad alcanzada en este juego combinatorio de prefijos y sufijos no deja de tener su interés en un género todavía expuesto a la lectura en voz alta, con un público también de oyentes para el que la onomástica podría ser un importante apoyo mnemotécnico y de reconocimiento.

\section{LA ADQUISICIÓN DEL NOMBRE}

"Y sabed, en resolución, que por el nombre se conoce al hombre» ${ }^{32}$. Este es el consejo que la Dama Viuda ofrece a su «Buen hijo» Percerval antes de partir de la Yerma Floresta Solitaria, y podría decirse que es la máxima caballeresca que guía la existencia de muchos de los protagonistas de estos libros. El nombre resume la vida de la persona, es heraldo de su fama, y por ello los caballeros en especial se esforzarán por dignificarlo y por preservarlo de toda mácula.

El nombre de pila es un nombre heredado, impuesto, del que el personaje quiere hacerse acreedor por méritos personales, a través de sus propias acciones. Como Perceval y Guinglain, algunos caballeros lo desconocen y quieren descubrirlo para encontrar también así su linaje ${ }^{33}$; otros lo encubren para hacerse dignos de él. Lo cierto es que este nombre

30.- D. Alonso, «El hidalgo Camilote y el hidalgo don Quijote», RFE, XX (1933), p. 393. En el mismo grupo entraría el del gigante Quirieleysón de Montalván (Tirante, I, p. 240).

31.- F. Ynduráin, «Para una función lúdica del lenguaje», en Doce Ensayos sobre el lenguaje, Madrid, Fundación March, 1974, pp. 215-227.

32.- Chrétien de Troyes, Perceval o el Cuento del Grial, traducción del texto francés del siglo XII por Martín de Riquer, Madrid, Espasa-Calpe, Austral 1982, 3.a ed., p. 36. Recoge el sentir de otras muchas frases sentenciosas en las que se condensa la importancia que se le otorga al buen nombre: "Más que las riquezas vale el buen nombre» (Proverbios, XXII, 1), o el refrán "Murió el hombre e murió su nombre» de tan importante papel en los escritos, por ejemplo, de don Juan Manuel (vid. M. R. Lida de Malkiel, La idea de la Fama en la Edad Media Castellana, México, FCE, 1983 (1.a ed. 1952), p. 216).

33.- La recuperación de la verdadera identidad por parte del caballero a través de la adquisición del auténtico nombre aparece formulada en los romans desde Chrétien de Troyes, por ejemplo en el Caballero de la Carreta o en el Perceval. Por su parte la ocultación del nombre posee en el roman la función de producir intriga en el auditorio y su desvelamiento marca en la estructura de la obra el comienzo de una nueva parte, como explica V. Cirlot en su edición de Renaut de Beaujeu, El Bello Desconocido, Madrid, Siruela, 1983, p. 105, nota 53. También puede verse en El Cementerio Peligroso, anónimo roman artúrico en verso donde Gauvain asume conscientemente su supuesta muerte y renuncia a su nombre: «No os puedo decir mi nombre - le responde Gauvain-, pues lo he perdido y no sé quién me lo ha robado», El Cementerio Peligroso, ed. de V. Cirlot, Madrid, Siruela, 1984, p. 71. 


\section{MARÍA CARMEN MARÍN PINA}

de pila no los identifica a lo largo de su existencia y que se oculta con otros apelativos para protegerlo o glorificarlo. Son estos sobrenombres adquiridos los que en definitiva resumen la vida del personaje y dan también pleno sentido al antropónimo recibido.

Los caballeros, protagonistas de unos libros a los que dan título con su propio nombre, suelen cambiar de apelativo poco después de ingresar en el mundo de la caballería, tras el iniciático rito de la investidura. Como en las órdenes religiosas donde los novicios renuncian a su antiguo nombre para ingresar en la nueva vida, los noveles caballeros cambian el suyo al iniciar su deambular. La caballería medieval, que no en vano sufrió un proceso de espiritualización y cuya máxima principal era la defensa de la fe cristiana y de Dios, pudo verse influida por esta costumbre que después también practican los caballeros literarios, incluido don Quijote $(D Q, \mathrm{I}, 19, \mathrm{p} .191)$. Como explica el hidalgo manchego a su escudero, el novel caballero se bautiza con un nuevo «nombre apelativo». El Donzel del Mar descubre entonces su verdadera identidad y por algún tiempo se llama Amadís de Gaula; el novel Primaleón la encubre cuando sale de la corte bajo el nombre del Caballero de la Roca Partida; Palmerín de Inglaterra se hace pasar por el Caballero de la Fortuna; Floriano del Desierto, por el Caballero del Salvaje ${ }^{34}$, etc., apelativos que pueden ir cambiando a medida que progresan en sus hazañas. En todos los casos el nombre se considera definición de la persona y por ello siempre que el caballero cambic de estado y de sentimientos lo modificará.

La onomástica también concuerda en este sentido con el curso de sus amores. Al perder el amor de Oriana, Amadís se llama simbólicamente Beltenebros; Lisuarte, al quedar privado del de Onoloria, inicia una nueva vida, cambia sus armas y se hace llamar el Caballero Solitario, «porque, según de la manera que iva, aquel nombre más que otro le convenía” (Lisuarte de Grecia, fol. 1viij v), lo mismo que Florendos se hace llamar el Caballero Triste, «porque también en aquel tiempo disfavores y olvidos de su señora le traían algo triste» (Palmerín de Inglaterra, p. 106 a). Si la ruptura amorosa conlleva un cambio de identidad, también lo exige a veces la conquista. Por amor los caballeros cambian de profesión y de nombre para alcanzar los favores de una dama. Por el amor de Flérida ${ }^{35}$, don Duardos se hace hortelano y se llama Julián (Primaleón); por el de Archisidea, Rogel de Grecia se transforma en el pastor Archileo y en el caballero Constantino (Florisel de Niquea ${ }^{36}$ ). El ciclo vital de muchos personajes se configura de este modo a través de su onomástica, que si en algunos casos puede ser muy sugerente, en la mayoría resulta hastante primaria y muy mecánica, porque los personajes van adoptando nombres cada vez más genéricos y menos simbólicos ${ }^{37}$.

El sobrenombre se conforma por lo general con el término caballero modificado por un sintagma determinante alusivo a su acompañante, al emblema de su escudo, al color de sus armas, al estado anímico en el que se encuentra, etc. En la elección de estos

34.- El terna ha sido tratado por J. Amezcua, Metamorfosis del caballero. Sus ransformaciones en los libros de caballerías españoles, Iztapalapa, Universidad Autónoma Metropolitana, 1984, p. 23 y SS.

35.- El de Flérida es un nombre del que mucho se ha hablado por emplearlo Garcilaso en sus Eglogas II y III. R. K. Spaulding, "And Who is Flérida?», $H R$, VI (1938), pp. 76-77, lo eleva a la categoría de nombre literario, como Filis, Amarilis, y lo rastrea en textos poéticos del Siglo de Oro. H. Iventosch, op. cit., p. 100, lo considera propio de la onomástica bucólica.

36.- Vid. S. Cravens, op. cit., p. 87.

37.- Esto es algo que se aprecia ya en el Amadís de Gaula, como muy bien ha estudiado Juan Manuel Cacho, ed, cit., p. 148, y que se generaliza en los textos posteriores. 
nombres analíticos se destaca primeramente su condición caballeresca, que es la que se está poniendo a prueba y la que le reportará fama y prestigio. En segundo lugar, un atributo por el que se distinguirá del resto de caballeros y que permitirá a los autores simbólicos juegos. El más practicado es aquel en el que, siguiendo una costumbre extendida en el mundo caballeresco ${ }^{38}$, las armas parlantes hacen juego con el nombre y conjuntamente vaticinan o simbolizan el estado vital del personaje. Así, por ejemplo, Lisuarte porta unas armas con una cruz colorada en medio del escudo «en señal de la qu'él en los pechos tenía» (Lisuarte, fol. xxxviij v) y por ambas señales un enano lo llama el Caballero de la Vera Cruz (Lisuarte, fol. xliiij r), nombre por el que se le conoce hasta su ruptura con Onoloria. Floriano «traía el escudo en canpo blanco un salvaje con dos leones por una trailla» (Palmerin de Inglaterra, p. 24 a), emblema alusivo al padre adoptivo que lo ha criado (p. 9 a) y a la vida que hasta entonces ha llevado (p. 14 b), mientras que su hermano Palmerín lleva en sus primeras empresas en el escudo, en campo azul, la rueda de la fortuna (p. 33), divisa que le da el nombre de Caballero de la Fortuna. Don Quijote, por otro nombre conocido como el Caballero de la Triste Figura, perpetúa tal práctica y, como le dice a Sancho, «para que mejor me cuadre tal nombre, determino de hacer pintar, cuando haya lugar, en mi escudo una muy triste figura» $(D Q, \mathrm{I}, 19, \mathrm{p} .191)$.

Con estos sobrenombres los caballeros disimulan su identidad y tienen libertad para moverse sin dificultad por distintos escenarios sin ser reconocidos. La defensa de estos nombres provoca igualmente aventuras de diferente signo. Por afamarlo emprenden todo tipo de empresas, lo mismo que por defender el de sus amadas - de las que se han podido enamorar de oídas - participan en torneos y desafíos. Por ocultarlo se enfrentan también a toda suerte de peligros. Conocer el nombre del personaje supone ejercer cierto dominio sobre él, por ello muchas veces los caballeros guardan celosamente el suyo y su encubrimiento provoca discusiones y enfrentamientos de fuerte tensión narrativa. Al negarse a descubrir su identidad o la de sus amadas se les prohibe a veces el paso por florestas, puentes o castillos; se enfrentan con sus hermanos o progenitores sin quc la llamada de la sangre sirva en este caso para alertarlos, etc. Sólo el lector posee en tales casos la clave para deshacer los enredos y los equívocos surgidos.

En conclusión, el nombre propio es en los libros de caballerías un elemento indispensable en la configuración del personaje y en el desarrollo de algunas de sus aventuras. Es también un pasatiempo verbal, un juego de artificio nominal en el que los autores del género ponen a prueba su ingenio y el de su público. Como rasgo pertinente del género lo apreció Cervantes, que, en palabras de Pedro Salinas ${ }^{39}$, hizo de cada nombre una aventurilla librada por sílabas contra sílabas y fonética contra significado. A fuerza de nombrar, Don Quijote y todos aquellos que deseaban confundirlo consiguieron recrear el imaginario mundo de los libros de caballerías, unos libros en los que el nombre es también en muchos sentidos una apasionante aventura.

38.- M. Keen, La caballeria, Barcelona, Ariel, 1986, p. 175. M. Pastoureau, La vida cotidiana de los caballeros de la Tabla Redonda, Madrid, Temas de Hoy, 1990, p. 125 y ss.

39.- P. Salinas, art. cit., p. 103. 